\title{
The cost of health workforce gaps and inequitable distribution in the Ghana Health Service: An analysis towards evidence-based health workforce planning and management.
} \author{
0620-6010 \\ Hamza Ismaila \\ Ghana Health Service \\ Anna Plange \\ Ghana Psychology Council \\ Victor Francis Ekey \\ Ghana Health Service \\ Abdul-Majeed Ahmed \\ Deceased \\ John Koku Awoonor-Williams \\ Ghana Health Service \\ Juliet Nabyonga-Orem \\ World Health Organisation
}

James Avoka Asamani ( $\nabla$ asamanij@who.int )

World Health Organisation, Regional Office for Africa, Intercountry Support Team for Eastern and Southern Africa (IST/ESA) https://orcid.org/0000-0003-

\section{Research}

Keywords: Human Resources for Health, Maldistribution, Health Workforce Distribution, Staffing Norms, Human Resource Gaps Analysis, Health Workforce policy

Posted Date: April 20th, 2020

DOI: https://doi.org/10.21203/rs.3.rs-21946/v1

License: (c) (i) This work is licensed under a Creative Commons Attribution 4.0 International License. Read Full License

Version of Record: A version of this preprint was published at Human Resources for Health on March 31st, 2021. See the published version at https://doi.org/10.1186/s12960-021-00590-3. 


\section{Abstract \\ Background:}

Despite tremendous health workforce efforts which has resulted in increases in the density of physicians, nurses and midwives from 1.07 per 1,000 population in 2005 to 2.65 per 1,000 population in 2017 , Ghana continue to face sub-optimal levels of health workforce alongside inefficient distribution. This paper reports on the use of a nationally agreed health facilities staffing standard to quantify the aggregate number of health workers who are inequitably distributed the associated cost implications as well as how the findings are being used to shape health workforce policy, planning and management.

\section{Methods:}

We conducted health workforce gap analysis for all health facilities of the Ghana Health Service in 2018 in which we compared a nationally-agreed evidencebased staffing standard with the prevailing staffing situation to identify need-based gaps and inequitable distribution. The cost of the prevailing staffing levels was also compared with the stipulated standard and the staffing cost related to inequitable distribution was estimated.

\section{Results:}

It was found that the Ghana Health Service needed 105,440 health workers to meet its minimum staffing requirements as at May 2018 vis-à-vis its prevailing staff at post of 61,756 thereby leaving unfilled vacancies of 47,758 (a vacancy rate of $41 \%$ ) albeit significant variations across geographical regions, levels of service and occupational groups. Of note, the crude equity index showed that in aggregate, the best staffed region was 2.19 times better off than the worst staffed region. The estimated cost (comprising basic salaries, market premium and other allowances paid from central government) of meeting the minimum staffing requirements was estimated to be GHç2,358,346,472 (US\$521,758,069) while the current cost of staff at post was GHç1,424,331,400

(US\$315,117,566.37), resulting in a net budgetary deficit of 57\% ( US\$295.4 million) to meet the minimum requirement of staffing for primary and secondary health services. Whilst the prevailing staffing expenditure is generally below the required levels, an average of $22 \%$ (range: $14-50 \%$ ) across the levels of primary and secondary healthcare were spent on staff deemed to have been inequitably distributed, hence provides scope for rationalisation. We estimate that the net budgetary deficit of meeting the minimum staffing requirement could be drastically reduced by some $30 \%$ just by redistributing the inequitably distributed staff.

\section{Policy Implications:}

Efficiency gains could be made by redistributing the 14,142 staff deemed to be inequitably distributed, thereby narrowing the existing staffing gaps by $30 \%$ to 33,616 , which could, in turn, be filled by leveraging synergistic strategy of task sharing and/or new recruitments. The results of the analysis provided insights that have shaped and continue to influence important policy decisions in health workforce planning and management in the Ghana Health Service.

\section{Introduction}

Globally, many health systems continue to grapple with a myriad of Human Resources for Health (HRH) challenges such as mismatches between the need for, demand for and supply of health workforce which are largely underpinned by low levels of training outputs, insufficient remuneration, inadequate funding and migration among others [1]. Particularly in the Africa Region, health workforce-related challenges remain one of the major threats to the attainment of the Sustainable Development Goal (SDG) three including Universal Health Coverage (UHC). If the lessons from the erstwhile Millennium Development Goals (MDGs) are anything to go by, the degree of success in this respect will be highly linked to the availability, accessibility and quality of the health workforce, an element of the health system that remains thorny; and has been linked to observed disparities in some health outcomes [2, 3]. There are, therefore, genuine concerns about the ability of the countries to step up efforts for the realisation of the SDGs, particularly SDG3 given the chronic health workforce challenges confronting the Africa region.

In the context of Ghana, various initiatives and activities are being implemented or scaled-up towards the attainment of UHC and SDG 3 by the year 2030 $(\mathrm{MOH}, 2015)$. The Ghana National Health policy, the Health Sector Medium Term Development Plan (HSMTDP 2018-2021 and earlier ones) are all geared towards ensuring Universal Health Coverage and strengthening the health system to effectively respond to the health needs of its citizens including health emergencies [4-7]. Consequently, there have been enormous efforts in the expansion of healthcare infrastructure, social health insurance coverage as well as training and employment of the health workforce.

Ghana has over the last decade increased the production and retention of its health workforce resulting in tremendous increases in the density of physicians, nurses and midwives from 1.07 per 1,000 population in 2005 to 2.65 per 1,000 population in 2017 [8]. These efforts have not only resulted in Ghana being cited as a country on a good footing towards UHC but also a leading producer of physicians, nurses and midwives in sub-Saharan Africa [9]. Nonetheless, some reports and published literature assert that Ghana's HRH stock may not be optimal and is plagued with inefficient distribution [10-13]. For instance, Scheffler et al [13] showed a serious deficit in the number of physicians, nurses and midwives in Ghana by 2015 which later estimates puts at $42 \%$ gross deficit in HRH availability but much worse amongst specialised groups of health professionals [14].

The maldistribution of available staff has manifested either as aggregate (absolute) or relative (skill-mix distortions) [15]. Aggregate or absolute maldistribution occurs when the composite of the HRH is distributed in a manner skewed against geographical region(s) or special population groups. On the other hand, relative maldistribution or skill-mix distortions is said to have occurred when highly skilled health workers are concentrated in certain locations 
(usually urban areas) whilst low skilled workers are also concentrated in the other locations (usually rural and under-served areas) [16]. In either situation, the population is likely to seek health services from the health facilities in locations with the requisite HRH which in turn increases workload in those facilities giving rise to a legitimate clamour for more staff. If not addressed, this forms a vicious cycle of 'inequity breeding inequity'. A redistribution of the health workforce based on needs assessment using a nationally agreed evidence-informed standard or norm can be an important step to addressing the inequalities in HRH distribution and its impact on health care delivery.

As part of efforts to address HRH shortages and maldistribution within the health sector of Ghana, the Ministry of Health (MOH) and its partners developed a staffing standard (known as staffing norms) for publicly-funded healthcare facilities in the country [17]. This HRH planning tool developed based on the World Health Organisation (WHO) recommended Workload Indicators of Staffing Needs (WISN) method, gives an indication of the calibre and number of health workers required in a given health care setting based on their workload. The process of WISN for development of staffing is reported elsewhere [18].

Notwithstanding that the staffing norms have been widely accepted by stakeholders and are being used by the Ghana Health Service (GHS) since 2015 for workforce planning and deployment, turning the tide of inequitable health workforce distribution remains a challenge. This is also in a context where several studies have revealed significant health system inefficiencies including the health workforce [19-22]. For instance, it is estimated that each health centre in Ghana could save at least US $\$ 7,062$ annually if they were more efficient [21] which represents about $15 \%$ of their US\$44,638 annual budgetary requirement for service delivery [23]. A large portion of the inefficiencies have been attributed to the health workforce in terms of inefficient distribution [24] and sub-optimal productivity [25].

To address the aforesaid challenge from a health workforce planning perspective, Ministry of Health (MOH) and its partners have been desirous of an analysis of the workforce gaps and cost based on the newly developed staffing norms [26]. This paper seeks to illustrate the use of a nationally agreed health facilities staffing standard to identify in aggregate terms, the inequitable distribution of the health workforce and associated cost implications as well as how it is being used to shape health workforce policy, planning and management.

\section{Overview of the Public Health Sector in Ghana}

Ghana's population was estimated at $28,687,274$ (the year 2016) with an annual growth rate of $2.7 \%$ [27]. The country at the time of analysis was divided into ten (10) political and administrative regions, which are further divided into 254 districts (the country's regions increased to 16 in 2019 ). Each district is also divided into sub-districts and communities which health service delivery is administratively and operationally aligned with. The GHS and Teaching Hospitals Act, 1996, Act 525 vests in GHS the mandate to provide primary and secondary health care services to people living in Ghana. This is complemented by private institutions and quasi-governmental institutions. The Teaching Hospitals as per Act 525 is mandated with the provision of tertiary health care services to the people living in Ghana. This leaves the Ministry of Health with a core responsibility for policy formulation and resource mobilisation.

In descending order of complexity in the health service delivery hierarchy are Teaching Hospitals (THs) at the top, which are semi-autonomous national referral hospitals with a mandate of managing complex health problems, research and staff training. Each TH is linked to a university to enhance its functions. The GHS which is by far the largest health service delivery agency of the $\mathrm{MOH}$ provides about $60 \%$ of outpatient and inpatient services and nearly all preventive public health care services [5]. In total, the GHS managed about 4,507 health facilities in 2018 of which $0.2 \%$ are secondary level (Regional) Hospitals, $3 \%$ are District (Primary) Hospitals, and 77\% are Community-based Health Planning and Service (CHPS) [28], which is the vehicle for delivering Primary Health Care (PHC) [29]. See Table 1 for the number of health facilities managed by GHS.

Table 1

Health Facilities Managed by GHS, 2018
\begin{tabular}{|ll|}
\hline Type of Health Facility & Number \\
\hline CHPS & 3,463 \\
\hline Health Centre & 871 \\
\hline Polyclinic & 36 \\
\hline District (Primary) Hospital & 127 \\
\hline Regional Hospital & 10 \\
\hline Grand Total & $\mathbf{4 , 5 0 7}$ \\
\hline
\end{tabular}

\section{Source: District Health Management Information System - 2 (DHIMS-2)}

The Regional Hospitals (RHs) are situated in the regional capitals to provide a secondary level of specialised health care and serve as referral centres for all District Hospitals in each region. On the other hand, District Hospitals (DHs) provide basic and emergency healthcare and have catchment areas coterminous with political districts or a population of 100,000-200,000. Sub-districts are served by Health Centres (HCs), which provide basic curative and preventive services. These are intended to serve populations of about 20,000. In urban areas, however, their capacity may be enhanced to become polyclinics where they serve populations larger than 20,000. At the community level, the main service delivery facilities for preventive services and treatment of minor ailments are CHPS that may have a physical structure (Compound) or not. These are intended to serve a population of 5000 or 750 households and maybe coterminous with electoral areas [29]. The statistics reported in this paper relate to health facilities managed by GHS, from Regional Hospitals through District Hospitals, Health Centre/Polyclinics to CHPS. Thus, Teaching Hospitals, Mission Health Facilities, Quasi-Government Health Facilities and Private-for-Profit Health Facilities have not been included in the analysis due to data-related challenges.

Page $3 / 12$ 


\section{Tools And Methods Analytical Framework}

Based on the Health Sector Staffing Norms [18, 30], the prevailing staffing situation of all health facilities of GHS was compared with their staffing requirement in which two levels of comparison were made: absolute $\mathrm{HRH}$ gaps and relative $\mathrm{HRH}$ gaps (staff-availability ratio).

\section{Establishing Absolute HRH Gaps}

The difference between the current staffing levels and the required number for a particular cadre in a facility was considered as the Absolute HRH Gap using the formulae below

Absolute HRH Gap = Current number - Required Number ....Eq. 1

This provided the actual number of understaffing or overstaffing of a particular cadre of staff in a health facility. A positive gap indicated overstaffing whereas a negative gap indicated understaffing.

\section{Establishing Relative HRH gaps (Staff-Availability Ratio, SAR)}

This measures the current staffing level (of a cadre of staff) as a ratio of the required number of staff as per the staffing norms.

$$
S A R=\frac{\text { Current Number of HRH }}{\text { Required Number of HRH based on Staffing Norms }}
$$

... Eq. 2

The SAR shows the amount of work pressure on the current staff and its interpretation is similar to that of WISN ratio [31]. SAR of 1 indicates sufficient staff or an optimal staffing level. However, SAR less than 1 shows understaffing whilst SAR greater than 1 indicates overstaffing in the facility.

The extent of understaffing or overstaffing is given as the difference between the desired SAR and the actual SAR. Thus, the given SAR minus 1 gives the magnitude of work overload (in the case of understaffing) or under-load (in the case of overstaffing).

The extent of overstaffing or understaffing $=S A R-1 \ldots$ Eq. 3

\section{Costing of the Staffing Norms and Gaps}

A conservative approach was used in estimating HRH cost from the perspective of Central Government. The cost drivers included in the analysis are those budgeted for by the MoH/GHS and paid from the government's consolidated fund. With this perspective, HRH cost incurred by local health facilities were not included. The main cost drivers considered for the analysis included

- Gross annual salaries

- Gross market premium (this is an allowance paid to health workers supposedly in short supply)

- Other allowances (such as housing, on-call duty facilitation, fuel, utility)

There is salary differentiation between various grades within the staff categories. For this study, we used a Weighted Average Method (WAM) to determine the weighted average salary of the staff category from the public sector salary scale of the Government of Ghana (GoG). The WAM was carefully selected having considered other alternative options such as the Simple Average of a category's annual salary and starting salary of the first grade in each staff category. This method was most preferred as it is not affected by extreme salary values and staff numbers within a category. It seeks to determine the relative staff grade numbers in each staff category vis-a-vis their respective corresponding annual salary per grade. The steps used are as follows:

The Weight $(\mathrm{W})$ in each category was determined by the number of staff on the grade (N) divided by the Total Number of staff (TN) in the category, mathematically expressed as

$W=N / T N \ldots$... 4

The weight (W) was then multiplied by the related Staff Cost (SC) resulting in the Weighted Staff Cost (WSC) for the particular grade. The summation of the Weighted staff cost for each grade determined the Weighted Average Staff Cost (WAC) for the category. These are expressed as follows:

SC = annual salary + market premium + other selected allowances drawn from the Gov't Consolidated Fund ... Eq. 5

$W S C=W \times S C \ldots E q .6$

$W A C=\sum W S C \ldots E q .7$

Expected staff cost of a category $(E C)=T N \times W A C \ldots$ Eq. 8 
$H R$ cost variance $=E C-C C . . . E q .10$

A negative HR cost variance depicts the cost of inefficiently distributed staff whilst a positive cost variance represents the cost of HRH shortfall (i.e. the amount of money needed to meet the Minimum Staffing Requirement). It must be noted that where the HR Cost Variance is zero, then the Minimum Staffing Requirement has been met.

\section{Data sources}

A three-year trend (2015-2018) of outpatient and inpatient data, used as proxies for workload or service utilisation, was extracted from the District Health Information Management System version 2 (DHIMS-2), the health data repository in Ghana. The health sector staffing norms classify health facilities according to their workload levels (using outpatients and inpatients as proxies) for HRH allocation [32, 33]. Based on the staffing norms, the workload data was used to identify the staffing requirements of each health facility in the GHS for 2018. The current staffing levels (number of the various cadres) as of May 2018 in each health facility were obtained from the individual health facility managers during a nationwide HRH gap analysis exercise.

\section{Results}

\section{Aggregate Human Resources for Health (HRH) Gaps by Region}

Based on the minimum staffing requirement of the Health Sector Staffing Norms, the gap analysis revealed that, in aggregate, 105,440 health workers were needed to meet the minimum staffing need the GHS as at May 2018. However, a total of 61,756 were accounted for by the various districts and health facilities as their health workforce at post. This meant a staffing Gap or vacancies of 47,758 were unfilled at GHS. Thus, as at the end of May 2018 , GHS had only $59 \%$ of its aggregate staffing requirement leaving a vacancy rate of $41 \%$. These aggregate figures, however, varied widely across various categories of staff and geographical locations. Table 2 provides details on the aggregate HRH requirements and Gaps for all Regions.

Table 2

Aggregate HRH Requirements and Gaps by Region (All Staff Categories)

\begin{tabular}{|lllll|}
\hline Region & Total Staff Required (a) & $\begin{array}{l}\text { Total at Post } \\
\text { (b) }\end{array}$ & $\begin{array}{l}\text { Total HR Gaps } \\
(\mathbf{c}=\mathbf{a}-\mathbf{b})\end{array}$ & Staff Availability Ratio (SAR = b/a) \\
\hline Ashanti & 13,730 & 7,854 & 6,209 & $57 \%$ \\
\hline Brong Ahafo & 10,510 & 5,009 & 5,777 & $48 \%$ \\
\hline Central & 8,283 & 5,366 & 3,245 & $65 \%$ \\
\hline Eastern & 14,627 & 6,390 & 8,579 & $44 \%$ \\
\hline Greater Accra & 9,317 & 8,497 & 1,041 & $91 \%$ \\
\hline Northern & 12,716 & 9,335 & 4,233 & $73 \%$ \\
\hline Upper East & 6,643 & 4,011 & 3,038 & $60 \%$ \\
\hline Upper West & 7,606 & 3,169 & 4,757 & $42 \%$ \\
\hline Volta & 10,800 & 5,738 & 5,490 & $53 \%$ \\
\hline Western & 11,208 & 6,387 & 5,389 & $57 \%$ \\
\hline National & 105,440 & 61,756 & 47,758 & $59 \%$ \\
\hline Crude Equity Index (Highest /Lowest) & & & 2.19 \\
\hline
\end{tabular}

The results depicted in Table 2 show Greater Accra region has the highest Staff Availability Ratio (SAR) of 91\% followed by the Northern region with SAR of $73 \%$ the lowest being Upper West Region with SAR of $42 \%$. Of note, the crude equity index showed that in aggregate, best staffed region (Greater Accra) was 2.19 times (or 219\%) better off than the worst staffed region (Upper West).

\section{Descriptive Analysis of Staff Availability Across Levels of Health Facilities}

As shown in Table 3 the total number of staff required at the CHPS zones and compounds is about 14,670 ( $13.9 \%$ of the overall staffing requirements), while those currently at post are 10,082 representing SAR of $68.7 \%$. Thus, about 7,141 additional staff were required to fill the staffing gaps or vacancies at the CHPS level. About 827 out of 3,584 (23.1\%) CHPS included in the analysis had one (1) midwife at post while $3.2 \%(n=113)$ of CHPS had at least 2 midwives as recommended in national policy. Furthermore, about $44 \%(1,572$ out of 3,581$)$ of CHPS had only one (1) Community Health Nurse (CHN) assigned to the zone while additional $46 \%$ of CHPS had at least two (2) CHNs. Overall, 3,350 representing $93.5 \%$ of the number of CHPS included in this analysis had at least one (1) CHN. Of the 11,627 CHNs accounted for in this analysis, 6,150 (53\%) were deployed at CHPS while 3,763 (32\%) were placed at Health Centres with responsibilities for outreach services. 
Table 3

HRH Requirements and Gaps for Various Levels of Service Delivery

\begin{tabular}{|lllll|}
\hline Type of Health Facility & Total Staff Required (a) & $\begin{array}{l}\text { Total at Post } \\
\text { (b) }\end{array}$ & $\begin{array}{l}\text { Total HR Gaps } \\
(\mathbf{c}=\mathbf{a}-\mathbf{b})\end{array}$ & Staff Availability Ratio (SAR= b/a) \\
\hline CHPS & 14,670 & 10,082 & 7,141 & $68.7 \%$ \\
\hline Health Centre & 29,521 & 15,357 & 14,419 & $52.0 \%$ \\
\hline Polyclinic & 4,211 & 3,333 & 879 & $79.1 \%$ \\
\hline Primary Hospital & 45,068 & 24,817 & 21,094 & $55.1 \%$ \\
\hline Regional Hospital & 7,050 & 5,505 & 1,679 & $78.1 \%$ \\
\hline District Health Directorate & 3,390 & 1,456 & 2,048 & $42.9 \%$ \\
\hline Municipal Health Directorate & 1,371 & 701 & 744 & $51.1 \%$ \\
\hline Metropolitan Health Directorate & 162 & 70 & 93 & $43.2 \%$ \\
\hline National & 105,443 & $\mathbf{6 1 , 3 2 1}$ & $\mathbf{4 8 , 0 9 7}$ & $\mathbf{5 8 . 2} \%$ \\
\hline
\end{tabular}

Also, Health Centres required a total of 29,521 staff ( $28.0 \%$ of the overall staffing requirements) as compared to the current state where only 15,357 staff were available at post (52.9\% SAR). Consequently, about 14, 419 additional staff are required at Health Centres for optimal service delivery at this level. Particularly, only $47.1 \%$ (415 out of 882 ) of health centres had at least one (1) Physician Assistant and even more critically, just $5.8 \%$ ( $n=51$ ) of health centres had up to two (2) Physician Assistants. However, $90.8 \%$ of all Health Centres had at least one (1) midwife at post, leaving $9.2 \%$ of health centres without midwives.

While about 4,211 staff are required at Polyclinics, some 3,333 staff were at post at the time of the gap analysis (representing SAR of 79.1\%), leaving a staffing deficit of 879 . Similarly, Primary Hospitals require about 45,068 staff (which represents $42.7 \%$ of the overall staffing requirements) as compared to 24,817 that were at post (SAR of 55.1\%). Finally, Regional Hospitals needed a total of 7,050 compared with 5,505 that were at post representing SAR of 78.1\%. Consequently, there is a staffing gap of 1,679 across all Regional Hospitals.

All primary (district) hospitals had at least one General Practitioner (Medical Officer). This means that the so-called 'no man stations' or 'hospitals with no doctor' had been eliminated by 2018 . However, 16 hospitals (12.6\%) were still 'one-man stations" and only $59.1 \%$ of the hospitals, mostly in urban areas, had 3 or more General Practitioners. Also, $87.5 \%$ of the primary hospitals had at least 10 midwives at post whereas $92.2 \%$ of the hospitals recorded 15 or more General Nurses at post. However, just $61.7 \%$ of the hospitals had up to 35 or more General Nurses. Also, just 36 out of 127 Primary Hospitals (28.3\%) had Obstetrician \& Gynaecologist at post. Each Regional Hospital had at least two (2) Obstetricians \& Gynaecologists at post although only 3 Regional Hospitals had 3 or more Obstetrics \& Gynaecology specialists. Similarly, fewer than a quarter of the primary hospitals $(24.4 \%, n=31)$ had specialist surgeons while $18.1 \%$ of Primary hospitals and $90 \%$ of Regional Hospitals had Paediatricians at post. There was no primary or secondary hospital with a Dermatologist while only one (1) Regional Hospital had a Psychiatrist.

Regarding Critical Care Nurses (CCNs), less than a third of primary hospitals $(27.3 \%, n=35)$ were found to have at least one Critical Care Nurse at post. Thus, Critical Care Nurses are completely unavailable in over 70\% of primary hospitals. Similarly, two (2) Regional Hospitals also lacked Critical Care Nurses. Also, 43.3\% ( $n=55)$ of primary hospitals had qualified Peri-Operative Nurses. As low as $22 \%(n=28)$ of primary hospitals and $60 \%(n=6)$ of Regional Hospitals had trained Emergency Nurses. However, only 13 hospitals (10\%) had up to two (2) trained Emergency Nurses.

\section{Aggregate HRH Cost Estimates: Requirements, Deficits and Distributional Inefficiencies}

Using the Ministry of Health ( $\mathrm{MOH}$ ) and Ghana Health Service (GHS) perspective, the estimated cost (which includes salaries, market premium and other allowances paid from the consolidated fund), of meeting the minimum staffing requirements was estimated to be about $\mathrm{GH}(\mathbf{c} 2,358,346,472$ which is equivalent to US\$521,758,069 (using December 2017 Interbank Exchange Rate of US\$1: GH 4.52 ) while the current cost of the staff at post was estimated at GHç1,424,331,400 (US\$315,117,566). The GHS, therefore, required an additional budget of GH\$1,335,069,404 (US\$295,369,337) to meet the minimum requirement of staffing for the various levels of service delivery. This represented about $57 \%$ additional budgetary requirement to fill vacant posts to meet the minimum nationally-agreed staffing norms.

However, in some health facilities mostly in urban areas, it was observed that they had been staffed beyond the stipulated numbers in the staffing norms and could theoretically be deemed as inequitably distributed. The cost of this prevailing staff maldistribution across regions, districts and facilities (inefficient distribution of staff) was estimated at GHC $401,054,332$ (US\$88,728,835) annually. This represented $28.2 \%$ of the government's expenditure on the wage bill. It was observed that the prevailing cost of inefficient staff distribution in the Greater Accra Region is about GHç79,539,377 (US\$17,597,207.30) which was the highest among all the regions. The region's staffing cost based on numbers at post was estimated to be GHC211,487,566 (\$46,789,285) compared with the expected staffing cost (based on the staffing norms) of GHל $216,834,126(\$ 3,724,364)$, leaving inefficient staff distribution cost in the region representing $39 \%$ of their wage bill. Therefore, the potential efficiency savings from staff redistribution could offset the minimal staffing deficit if re-deployment of staff is pursued from areas of excess to areas of need in the region.

Also, the Northern and Ashanti regions were plagued with similar patterns of the high cost of inefficient staff distribution. For instance, while the Northern region is usually considered to be grossly understaffed, the analysis reveals that $36 \%$ of current staffing cost in the region is attributable to inefficient distribution which conservatively costs the government some GHç78,038,383 $(\$ 17,265,129)$ annually. In the same vein, $29 \%$ of the prevailing staffing cost in

Page 6/12 
the Ashanti region is attributable to inefficient distribution which amounts to potential efficiency savings of GHç53,274,031 (\$11,786,290.04) annually if redistribution is pursued in the region.

It is noteworthy, however, that the Eastern Region had the lowest cost of inefficient staff distribution of GHc23,017,244 (\$5,092,310.62) per annum which translated into $16 \%$ of the prevailing staffing cost. The region is, however, confronted with a significant shortage of health workforce which would also require a net investment of GHÇ198,814,906 $(\$ 43,985,598.67)$ over 5 years after the re-deployment of excess staff to meet their minimum staff requirement. See Table 4 for details of the expected staffing cost compared with the current cost and the potential efficiency savings that could accrue from staff redistribution across all regions.

It is worth noting, however, that the aforesaid costs varied significantly across different categories of health workers which a national summary is present in the supplementary table.

Table 4

Cost of Aggregate HRH Requirements, Gaps and inefficient distribution in Ghana by Regions.

\begin{tabular}{|c|c|c|c|c|c|c|c|c|c|}
\hline \multirow[t]{2}{*}{ Region } & \multicolumn{2}{|c|}{ Total Expected Cost } & \multicolumn{2}{|c|}{ Total Current Cost } & \multicolumn{2}{|c|}{$\begin{array}{l}\text { Cost of Inefficient Staff } \\
\text { Distribution }\end{array}$} & \multicolumn{2}{|c|}{ Total Cost of Shortage } & \multirow{2}{*}{$\begin{array}{l}\text { Proportion } \\
\text { of } \\
\text { Inefficiency } \\
\text { to Current } \\
\text { Cost }\end{array}$} \\
\hline & $(\mathrm{GHC})$ & US\$ & $(\mathrm{GHC})$ & US\$ & (GHC) & US\$ & $(\mathrm{GHC})$ & US\$ & \\
\hline Ashanti & $307,673,077$ & $68,069,265$ & $184,695,059$ & $40,861,739$ & $53,274,031$ & $11,786,290$ & $176,252,049$ & $38,993,816$ & $29 \%$ \\
\hline $\begin{array}{l}\text { Brong } \\
\text { Ahafo }\end{array}$ & $232,105,773$ & $51,350,835$ & $114,796,453$ & $25,397,445$ & $23,396,508$ & $5,176,219$ & $140,705,828$ & $31,129,608$ & $20 \%$ \\
\hline Central & $182,776,572$ & $40,437,295$ & $116,987,137$ & $25,882,110$ & $31,458,889$ & $6,959,931$ & $97,248,323$ & $21,515,116$ & $27 \%$ \\
\hline Eastern & $322,420,490$ & $71,331,967$ & $146,622,828$ & $32,438,679$ & $23,017,244$ & $5,092,311$ & $198,814,906$ & $43,985,599$ & $16 \%$ \\
\hline $\begin{array}{l}\text { Greater } \\
\text { Accra }\end{array}$ & $216,834,126$ & $47,972,152$ & $211,487,566$ & $46,789,285$ & $79,539,377$ & $17,597,207$ & $84,885,937$ & $18,780,075$ & $38 \%$ \\
\hline Northern & $290,656,714$ & $64,304,583$ & $217,152,425$ & $48,042,572$ & $78,038,383$ & $17,265,129$ & $151,542,672$ & $33,527,140$ & $36 \%$ \\
\hline $\begin{array}{l}\text { Upper } \\
\text { East }\end{array}$ & $148,811,404$ & $32,922,877$ & $92,074,647$ & $20,370,497$ & $24,167,133$ & $5,346,711$ & $80,903,890$ & $17,899,091$ & $26 \%$ \\
\hline $\begin{array}{l}\text { Upper } \\
\text { West }\end{array}$ & $171,496,126$ & $37,941,621$ & $69,139,832$ & $15,296,423$ & $18,871,455$ & $4,175,101$ & $121,227,749$ & $26,820,298$ & $27 \%$ \\
\hline Volta & $235,851,965$ & $52,179,638$ & $127,988,154$ & $28,315,963$ & $29,751,003$ & $6,582,080$ & $137,614,814$ & $30,445,755$ & $23 \%$ \\
\hline Western & $249,720,225$ & $55,247,837$ & $143,387,300$ & $31,722,854$ & $39,540,309$ & $8,747,856$ & $145,873,235$ & $32,272,840$ & $28 \%$ \\
\hline National & $2,358,346,472$ & $521,758,069$ & $1,424,331,400$ & $315,117,566$ & $401,054,332$ & $88,728,835$ & $1,335,069,404$ & $295,369,337$ & $28 \%$ \\
\hline
\end{tabular}

The analysis revealed significant health workforce expenditure gaps and inefficiencies for the various levels of healthcare delivery with the GHS. In particular, the expected annual staffing cost for CHPS is estimated at GHÇ231,823,176 (US\$51,288,313) as against prevailing expenditure of GHç191,693,352 $(\$ 42,410,033)-21 \%$ less than optimal wage bill related expenditure at the community level. However, despite this apparent workforce expenditure deficit, the total cost of inefficient staff distribution within CHPS is estimated at GHç95,147,366 $(\$ 21,050,302.21)$ annually. Thus, almost $50 \%$ of prevailing staffing cost at CHPS could be optimised via possible staff redistribution especially for Community Health Nurses which about 2,992 could be redistributed to cover $77 \%$ of the existing gaps for Community Health Nurses.

For Health Centres, the annual expected cost of staffing based on the staffing norms is estimated at GHÇ570,040,243 (US\$126,115,098) while the prevailing cost is estimated to be $\mathrm{GH}\langle 320,121,782$ (US\$70,823,403) but the prevailing cost also contains inefficient staff distribution which is estimated at GHÇ100,744,215 (US\$22,288,543), representing 31\% of the prevailing staffing expenditure. Therefore, the total cost of staff shortage could be ameliorated by about $29 \%$ if staff rationalisation is undertaken.

Furthermore, the annual expected cost of staffing Polyclinics is about GHç98,443,018 (US\$21,779,429) compared with a prevailing expenditure of

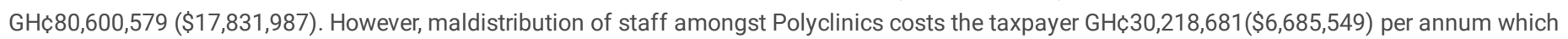
represents $37 \%$ of prevailing staffing cost. For Primary Hospitals, the total expected cost of staffing is estimated at GHç1,163,063,130 (US\$257,314,852) per annum whereas the prevailing cost of staffing is about GHç634,088,004 (US\$140,284,956.64) of which GHç120,239,721(\$26,601,708.19) or $19 \%$ is attributed to inefficient staff distribution.

Similarly, Regional Hospitals require an overall staffing cost of GHç197,989,928 (US\$43,803,081) compared to the prevailing expenditure of GHç149,837,220 (US\$33,149,827). About $27 \%$ (GHç40,162,967 or $\$ 8,885,612$ ) of the current cost is, however, attributable to inequitable distribution of staff which could offset nearly half of the additional staffing expenditure ( $\mathrm{GH} \zeta 88,315,674$ or $\$ 19,538,866)$ needed across all the Regional Hospitals.

From the foregoing, it is apparent that while current staffing expenditure is generally below expected levels, an average of 22\% (range: $14-50 \%$ ) of existing staffing cost across the levels of primary and secondary healthcare could be better optimised using staff rationalisation.

Page 7/12 
Table 5

Cost estimates for staffing requirements, gaps and inefficient distribution by type of health facility

\begin{tabular}{|c|c|c|c|c|c|c|c|c|c|}
\hline \multirow[t]{2}{*}{$\begin{array}{l}\text { Type of } \\
\text { Facility }\end{array}$} & \multicolumn{2}{|c|}{ Total Expected Cost } & \multicolumn{2}{|c|}{ Total Current Cost } & \multicolumn{2}{|c|}{$\begin{array}{l}\text { Total Cost of Inefficient } \\
\text { Distribution }\end{array}$} & \multicolumn{2}{|c|}{ Total Cost of Shortage } & \multirow{2}{*}{$\begin{array}{l}\% \text { of } \\
\text { Inefficienc } \\
\text { to Current } \\
\text { Cost }\end{array}$} \\
\hline & $\mathrm{GHc}$ & US\$ & $\mathrm{GHc}$ & US\$ & GHc & US\$ & GHc & US\$ & \\
\hline CHPS & $231,823,176$ & $51,288,313$ & $191,693,352$ & $42,410,034$ & $95,147,366$ & $21,050,302$ & $135,277,190$ & $29,928,582$ & $50 \%$ \\
\hline $\begin{array}{l}\text { Health } \\
\text { Centre }\end{array}$ & $570,040,243$ & $126,115,098$ & $320,121,782$ & $70,823,403$ & $100,744,215$ & $22,288,543$ & $350,662,676$ & $77,580,238$ & $31 \%$ \\
\hline Polyclinic & $98,443,018$ & $21,779,429$ & $80,600,579$ & $17,831,987$ & $30,218,681$ & $6,685,549$ & $48,061,119$ & $10,632,991$ & $37 \%$ \\
\hline $\begin{array}{l}\text { Primary } \\
\text { Hospital }\end{array}$ & $1,163,063,130$ & $257,314,852$ & $634,088,004$ & $140,284,957$ & $120,239,721$ & $26,601,708$ & $649,214,847$ & $143,631,603$ & $19 \%$ \\
\hline $\begin{array}{l}\text { Regional } \\
\text { Hospital }\end{array}$ & $197,989,928$ & $43,803,081$ & $149,837,220$ & $33,149,827$ & $40,162,967$ & $8,885,612$ & $88,315,674$ & $19,538,866$ & $27 \%$ \\
\hline $\begin{array}{l}\text { District } \\
\text { Health } \\
\text { Directorate }\end{array}$ & $71,349,138$ & $15,785,208$ & $27,744,496$ & $6,138,163$ & $3,901,849$ & 863,241 & $47,506,490$ & $10,510,285$ & $14 \%$ \\
\hline $\begin{array}{l}\text { Municipal } \\
\text { Health } \\
\text { Directorate }\end{array}$ & $28,256,462$ & $6,251,430$ & $13,683,188$ & $3,027,254$ & $3,027,632$ & 669,830 & $17,600,906$ & $3,894,006$ & $22 \%$ \\
\hline $\begin{array}{l}\text { Metropolitan } \\
\text { Health } \\
\text { Directorate }\end{array}$ & $3,417,796$ & 756,150 & $1,592,694$ & 352,366 & 336,300 & 74,403 & $2,161,401$ & 478,186 & $22 \%$ \\
\hline National & $2,364,382,891$ & $523,093,560$ & $1,419,361,317$ & $314,017,990$ & $393,778,730$ & $87,119,188$ & $1,338,800,304$ & $296,194,758$ & $27.75 \%$ \\
\hline
\end{tabular}

\section{Discussion}

Our analysis showed that as at the end of May 2018 GHS had only $59 \%$ of its aggregate staffing requirement leaving a vacancy rate of $41 \%$. However, vacancy rates varied across levels of service delivery, cadres of staff and geographical locations. Results show better staffing at the Polyclinic and Regional hospital level; generally, administrative staff compared to clinical staff and urban compared to rural regions. Noteworthy was the very low staff availability for Medical Specialties as Psychiatry, Neonatology and Cardiology, as well as Critical Care Nurses and Pharmacists. Results point to both absolute and relative gaps in staffing in the Ghana Health Service. This picture of inequitable distribution of HRH within the Ghanaian context is in tandem with the long-standing picture in the majority of sub-Saharan Africa countries, where the preference for postings is skewed in favour of urban settings and higher-level health facilities [3, 34].

There is a gap in financing HRH as well as inefficiencies in utilisation of the wage bill as evidenced in the cost of the inequitable distribution. The wage bill cost of inequitable distribution is an area that has not been explored extensively as a measure to reduce the gap in the wage bill. In our analysis inefficiencies in spending range from $16-38 \%$ across the different regions and from $14-50 \%$ across the different levels of health facilities. Although our analysis focussed solely on $\mathrm{HRH}$, inefficiencies in resource use in general has been demonstrated in Ghana's health sector where up to $65 \%$ of health facilities were found to be technically inefficient as they relatively used more resources than required for their level of output $[19,22,23,35]$. Others have argued that health centres alone could save some US\$7,062 annually [23] which could yield at least US\$6 million efficiency savings per annum.

The Staff Availability Equity Ratio (SAER) which is a measure of distributional disparity measured as the ratio of the best-staffed region to the worst staffed region was 2.17. This means that the worst staffed region (Upper West) was more than twice worst off than the best-staffed region (Greater Accra). This level of disparity in staffing situation between regions signalled high levels of inefficient staff distribution. It would, thus, be necessary to progressively monitor this indicator to track the impact of the implementation of the staffing norms.

The analysis also showed the $\mathrm{HRH}$ gaps for the regions ranged from 1,041 in the Greater Accra region to as high as 8,579 in the Eastern region, giving a staff availability ratio of $91 \%$ and $44 \%$ respectively. The $91 \%$ staff availability ratio of the Greater Accra region corresponds to international targets of at least $70 \%$ of nationally determined requirements [36]. The national picture of the HRH gaps stood at 47,708 with a staff availability ratio of $59 \%$. Thus, much needs to be done in terms of improving training outputs and recruitment to meet health workforce targets. Additionally, only polyclinics and regional hospitals were observed to have at least $70 \%$ of their staffing requirements with polyclinics having a staff availability ratio of $79.1 \%$ and regional hospitals having $78.1 \%$. Most polyclinics are located in urban areas so as the regional hospitals which partly explains their relatively better staffing situation. On the other hand, the CHPS level which on average had $68.7 \%$ of their staffing requirement is one flagship area of the primary health care system in Ghana where substantial investment is being made [37]. Nonetheless, it suggests to some degree the success of the CHPS policy in Ghana.

An amount of $\mathrm{GH} \otimes 1,335,069,404$ was required by the GHS to address the minimum staffing requirements for the various levels of service delivery; whilst the cost of current maldistribution across regions, districts and facilities stood at about $\mathrm{GH} \backslash 401,054,332$ representing $28.2 \%$ of current expenditure on staff at post. Regionally, the Greater Accra Region which is found to have the highest cost associated with inequitable distribution has also been cited in previous studies for a relatively very level of health workforce productivity [25]. In contrast, the Eastern Region was seen to be the region with the lowest cost of inequitable staff distribution needed a net investment of $\mathrm{GH} \otimes 198,814,906$ to address the HRH gaps in the region over the next five years.

\section{Conclusions}


The evidence presented show that despite the tremendous strides made to increase health workforce stock, the Ghana Health Service aggregately lacked at least $41 \%$ of its required staff in 2018 . The challenges of health workforce shortages is often exacerbated by distributional disparities. However, the cost associated with both challenges and inequitable distribution has been seldomly estimated to inform policy. Consistent with previous works from efficiency perspective, this analysis provides new insights that some $22 \%$ of the wage bill of Ghana Health Service is spent on health workers who are inequitably distributed if the health sector staffing norms of Ghana is used as the benchmark for distribution. Although the levels of health workforce budgetary deficits was as much as $57 \%$ on average, the cost of the inequitably distributed health workers could offset this budgetary deficit by almost $30 \%$. Investing in the employment of trained but unemployed heath workers [38] and using evidence for health workforce planning and policies is a pre-requites for addressing the aforesaid challenges. This analysis may only be a tip of the iceberg hence a comprehensive health labour market analysis imperative for holistic insights.

\section{POLICY IMPLICATIONS AND IMPACT}

The analysis provided insights into several policies and implementation issues that could be addressed to improve the overall staffing situation and equity within the Ghana Health Service. It made a substantial contribution to ongoing health workforce planning transformation within the GHS. These included:

- Improved budgetary allocation for recruitment of health workers: The overall shortfall in health worker availability was estimated at 61,900 but some 14,142 were also attributed to maldistribution, constituting $23 \%$ of the national shortfall. Thus, the net shortfall in staffing (if redistribution were to be made) was projected to be 47,758 across all categories of staff. This evidence was presented as part of the 2019 national budget planning process which contributed to the allocation of additional recruitment for the health sector in 2019 culminating the recruitment of 13,271 unemployed health workers [39]. However, this evidence-based planning needs to be further strengthened and sustained.

- Improving health workforce information: To ensure sustainability in the monitoring and analysis of the health workforce distribution and equity, a Human Resource Information and Management System, HRIMS (https://www.ghsnewhrims.org/) was developed and deployed within the context of the National Health workforce Account (NHWA) [40] which at the time of writing this paper had a data completion rate of over $90 \%$. The staffing norms and the gap analysis have been integrated into the HRIMS to sustainably repeat the analysis annually for decision-making on a real-time basis.

- Redistribution strategy: Of the 14,142 staff that were deemed to be inequitably distributed, 11,600 (82\%) constituted intra-regional distortions which required district and regional level redistribution. Only 2,542 (18\%) of the mal-distribution was inter-regional in nature and required headquarters-led or national level redistribution. Following extensive stakeholder deliberations, a draft redistribution concept was adopted, cost and the possible efficiency gains analysed over five years (this section is being reported in a separate paper). For future recruitments and/or postings, priority should be given to Region, Districts and Facilities with the least staffing requirement as per the staffing norm to ensure that they meet their minimum staffing requirements. Consequently, a moratorium should be placed on postings to regions/facilities with optimal staffing requirement (except for replacement of disengaged staff) until there was relative equity in the HRH situation across regions/facilities. To facilitate this, recruitment processes were made online with each region given a quota based on the workforce gaps identified in the analysis. The Public Services Commission of Ghana also adopted the health sector staffing norms as the official establishment/staffing ceiling for health facilities. Although this is largely a cost containment measure, it could contribute to addressing inequitable distribution of health workers.

- Health workforce production (training and education): The result of the analysis paints a picture of education market failure where the current production of HRH seemed not to be matching health workforce need [11]. For instance, there is the above-optimal availability of staff cadres such as auxiliary nurses or Enrolled Nurses (SAR:139\%), Dental Prosthesis Technicians (SAR:200\%), IT Managers (SAR:660\%), Public Health Officers-Nutrition (SAR:220\%) and Opticians (SAR:380\%). It would thus, be imperative for a comprehensive health labour market analysis to engender evidence-based policy dialogue at the highest level to correct the current education market failure in favour of the production of staff cadres high in demand but currently short in supply. The current situation(s) of only $24 \%$ of hospitals having Specialist Surgeons, $82 \%$ of Primary Hospitals having no Paediatricians and all primary hospitals lacking appropriately qualified Emergency Medicine Physician and Psychiatrist could easily be corrected if the norms were to inform the production of the health workforce.

- Leveraging task-sharing: Given that about $90 \%$ of the government's subvention to the public health sector goes into the payment of employee compensation, the fiscal space for additional recruitment of HRH is increasingly constrained. As a result, GHS Leadership could consider deepening its already adopted task-sharing approach, which allows middle and lower-level health professionals to assume duties and activities hitherto not part of their traditional roles. Allowing these middle and lower-level health professionals to perform hitherto untraditional roles, of course with additional training, will bring about a rapid expansion of access to essential healthcare services, increase efficiency, and reduce health worker training and wage bill costs (Padmanathan \& De Silva, 2013).

\section{Limitations of the analysis}

The analysis reported herein dealt with only one agency (the GHS) of the health sector in Ghana which accounts for some $65 \%$ of the public sector health workforce [41]. Therefore, the analysis provides a tip of the iceberg rather than a comprehensive view of the health workforce inequity in Ghana. For instance, it is well documented that nearly half of doctors in the public sector are congregated at two biggest teaching hospitals which are not part of this analysis [42]. Owing to increasing demand for curative services, some CHPS facilities were found to be operating at the level of Health Centres whiles others were said to have been converted to health centres with Physician Assistants assigned to them - against the stated CHPS policy of the government [29]. Similarly, some urban polyclinics were also found to be operating at the level of primary hospitals with medical specialist although they had not been officially designated so. These may have contributed to the need for higher levels of staffing in those facilities thereby increasing the magnitude of the inequitable distribution, but the lack of qualitative explanation to shed light on these should be considered a shortcoming of the analysis.

\section{Abbreviations}


CHPS

Community-based Health Planning and Services

$\mathrm{CHN}$

Community Health Nurse

$\mathrm{HRH}$

Human Resource for Health

GHS

Ghana Health Service

HWF

Health Workforce

$\mathrm{MOH}$

Ministry of Health

SAR

Staff Availability Ratio.

SDGs

Sustainable Development Goals

UHC

Universal Health Coverage

WHO

World Health Organization

\section{Declarations}

Acknowledgement: We express gratitude to Human Resource Directorate and the Policy, Planning, Monitoring and Evaluation Division of the Ghana Health Service as well as the WISN Technical Working Group for their contribution to the analysis. The World Health Organisation is also acknowledged for technical support during the analysis.

Funding: The health workforce gaps analysis was funded by DFID/UKAID as part of its support to the Ghana Health Service through the Maternal, Nutrition, and Child Health Project (MNCHP). However, the funder had no role in data acquisition, analysis and interpretation.

Availability of data and materials: The datasets supporting our conclusions are publicly available and will be provided upon request.

Authors' contributions: JAA, HI, AP and AMA contributed equally to data collection and analysis. JKAW together with JAA, FVE and HI conceived, and developed concept note for the analysis and JKAW obtained funding for it. JAA designed statistical models with support from HI and AMA. JAA, AP, HI and JNO developed the initial draft of the manuscript which all authors reviewed and approved the final version. JNO and JKAW oversaw the overall quality assurance of the analysis and manuscript.

Ethics approval and consent to participate: The work is based on publicly available data and did not involve the use of human subjects or animals. No ethical approval was required.

Consent for publication: All authors have approved the manuscript for submission.

Competing interests: The authors declare that they have no competing interests.

\section{References}

1. Bossert TJ, World Health Organization, editor. Assessing financing, education, management, and policy context for strategic planning of human resources for health. Geneva: World Health Organization; 2007.

2. Anand S, Bärnighausen T. Human resources and health outcomes: cross-country econometric study. The Lancet [Internet]. 2004 [cited 2016 Oct 10];364:1603-1609. Available from: .

3. 10.1186/1478-4491-7-4

Munga MA, Mæstad O. Measuring inequalities in the distribution of health workers: the case of Tanzania. Hum Resour Health [Internet]. 2009 [cited 2016 Oct 10];7. Available from: .

4. MOH. HEALTH SECTOR MEDIUM TERM DEVELOPMENT PLAN (HSMTDP). 2018-2021. Ministry of Health, Ghana; 2017.

5. MOH. Health Sector Holistic Assessment of the Health Sector Performance - 2015. Ministry of Health, Ghana; 2016.

6. MOH. The Health Sector Medium-Term Development Plan, 2014-2017 [Internet]. Ministry of Health, Ghana; 2014. Available from: .

7. $\mathrm{MOH}$. National Health Policy: Creating Wealth Through Health [Internet]. Ministry of Health, Ghana; 2007 [cited 2016 Jun 4]. Available from: .

8. GHS. Human Resource Directorate Annual Report for 2017. Ghana Health Service, Human Resource Directorate; 2018.

9. Campbell J, Buchan J, Cometto G, David B, Dussault G, Fogstad H, et al. Human resources for health and universal health coverage: fostering equity and effective coverage. Bull World Health Organ [Internet]. 2013 [cited 2017 Jan 29];91:853-863. Available from: 96862013001100853\&script=sci_arttext.

10. AHWO. Human Resources for Health Country Profile: Ghana, 2010. African Health Workforce Observatory; 2010. 
11. $10.1186 / \mathrm{s} 12960-020-0462-5$

Asamani JA, Amertil NP, Ismaila H, Akugri FA, Nabyonga-Orem J. The imperative of evidence-based health workforce planning and implementation: lessons from nurses and midwives unemployment crisis in Ghana. Hum Resour Health [Internet]. 2020 [cited 2020 Mar 6];18:16. Available from: .

12. Asamani JA, Naab F, Ofei AMA. Leadership styles in nursing management: implications for staff outcomes. J Health Sci [Internet]. 2016 [cited 2016 Apr 18];6:1-14. Available from: .

13. $10.1377 /$ hlthaff.28.5.w849 Scheffler RM, Mahoney CB, Fulton BD, Dal Poz MR, Preker AS. Estimates Of Health Care Professional Shortages In Sub-Saharan Africa By 2015. Health Aff (Millwood) [Internet]. 2009 [cited 2016 Jun 3];28:w849-62. Available from: .

14. Asamani JA, Chebere MM, Barton PM, D'Almeida SA, Odame EA, Oppong R. Forecast of healthcare facilities and health workforce requirements for the public sector in Ghana, 2016-2026. Int J Health Policy Manag. 2018;7:1040-52.

15. 10.1186/1478-4491-4-12 Dussault G, Franceschini MC. Not enough there, too many here: understanding geographical imbalances in the distribution of the health workforce. Hum Resour Health [Internet]. 2006 [cited 2016 Aug 29];4:1. Available from: .

16. Asamani JA. Equitable Access to a Functional Health Workforce in the Africa Region. 2016; Available from: php? option=com_docman\&task=doc_download\&gid=10561\&ltemid=2593.

17. MOH. Staffing Norms for the Health Sector. Ministry of Health, Ghana; 2018.

18. WHO. Workload Indicators of Staffing Need (WISN). Selected Country Implementation Experiences. Hum Resour Health Obs Ser [Internet]. 2016 [cited 2016 Jun 12];15. Available from: .

19. Alhassan RK, Nketiah-Amponsah E, Akazili J, Spieker N, Arhinful DK, de Wit TFR. Efficiency of private and public primary health facilities accredited by the National Health Insurance Authority in Ghana. Cost Eff Resour Alloc. 2015;13:23.

20. Kirigia JM, Emrouznejad A, Cassoma B, Asbu EZ, Barry S. A Performance Assessment Method for Hospitals: The Case of. Effic Health Syst Units Afr Data Envel Anal. 2015.

21. Novignon J, Nonvignon J. Improving primary health care facility performance in Ghana: efficiency analysis and fiscal space implications. BMC Health Serv Res. 2017;17:399.

22. Osei D, d'Almeida S, George MO, Kirigia JM, Mensah AO, Kainyu LH. Technical efficiency of public district hospitals and health centres in Ghana: a pilot study. Cost Eff Resour Alloc. 2005;3:9.

23. $10.1186 / \mathrm{s} 12913-017-2676-3$

Dalaba MA, Welaga P, Matsubara C. Cost of delivering health care services at primary health facilities in Ghana. BMC Health Serv Res [Internet]. 2017 [cited 2018 May 18];17. Available from: .

24. Appiah-Denkyira E, Herbst CH. Toward Evidence-Based Interventions for HRH. 2013 [cited 2017 Jan 29]. Available from: .

25. Vujicic M, Addai E, Bosomprah S. Measuring Health Workforce Productivity: Application of a Simple Methodology in Ghana. 2009 [cited 2015 Dec 5]; Available from: .

26. MOH. Holistic Assessment of the Health Sector Programme of Work 2013 [Internet]. Accra: Ministry of Health, Ghana; 2014. Available from: .

27. Ghana Statistical Service. National population and housing census, year 2010 report. 2012.

28. MOH. District Health Management Information System-Vesion 2 (DHIMS-2). [Internet]. Centre for Health Information Management (CHIM) -Ministry of Health; 2016. Available from: FE74625334BE2AF90B42A05B840B.

29. MOH. National Community-Based Health Planning and Services (CHPS). Policy: Accelerating attainment of Universal Health Coverage and bridging the access inequity gap. Ministry of Health, Ghana; 2015.

30. $\mathrm{MOH}$. Staffing Norms for the Health Sector of Ghana [Internet]. Ministry of Health, Ghana; 2014. Available from: .

31. World Health Organization. Workload indicators of staffing need. 2010 [cited 2015 Oct 11]; Available from: .

32. MOH. Staffing Norms for the Health Sector of Ghana (Volume 1). Ministry of Health, Ghana; 2015.

33. WHO. WORKLOAD INDICATORS OF STAFFING NEED (WISN). SELECTED COUNTRY IMPLEMENTATION EXPERIENCES [Internet]. World Health Organization; 2016 [cited 2016 May 17]. Available from: .

34. Ferrinho P, Siziya S, Goma F, Dussault G. The human resource for health situation in Zambia: deficit and maldistribution. Hum Resour Health [Internet]. 2011 [cited 2015 Dec 4];9:30. Available from: .

35. Akazili J, Adjuik M, Jehu-Appiah C, Zere E. Using data envelopment analysis to measure the extent of technical efficiency of public health centres in Ghana. BMC Int Health Hum Rights Springer. 2008;8:11.

36. WHO WHO. Global strategy on human resources for health: workforce 2030. 2016.

37. Nyonator FK, Awoonor-Williams JK, Phillips JF, Jones TC, Miller RA. The Ghana community-based health planning and services initiative for scaling up service delivery innovation. Health Policy Plan. Oxford University Press; 2005;20:25-34.

38. 10.1186/s12960-020-0462-5

Asamani JA, Amertil NP, Ismaila H, Akugri FA, Nabyonga-Orem J. The imperative of evidence-based health workforce planning and implementation: lessons from nurses and midwives unemployment crisis in Ghana. Hum Resour Health [Internet]. 2020 [cited 2020 Mar 6];18:16. Available from: .

39. GHS. Human Resource Annual Report - 2019. Accra: Ghana Health Service; 2020.

40. GHS. Human Resources Information and Management System (HRIMS) [Internet]. Ghana Health Service; 2020 [cited 2020 Apr 5]. Available from: .

Page $11 / 12$ 
41. GHS. Human Resource Annual Report - 2018. Accra: Ghana Health Service; 2019.

42. GHS. Human Resource Annual Report - 2017. Accra: Ghana Health Service; 2017.

\section{Supplementary Files}

This is a list of supplementary files associated with this preprint. Click to download.

- Supplementarytable.docx 